\title{
Space-Based Ka-Band Direct Radiating Phased Array Antenna Architecture For Limited Field Of View
}

\author{
Rainee N. Simons \\ NASA Glenn Research Center \\ MS 54-1, 21000 Brookpark Road \\ Cleveland, OH 44135 USA \\ (E-mail: Rainee.N.Simons@nasa.gov)
}

\begin{abstract}
The paper presents the results of an ongoing study to investigate the feasibility of designing a direct radiating phased array antenna on a relay satellite for limited field-of-view.
\end{abstract}

Keywords-Array antenna; beam forming network; gallium nitride; solid-state power amplifiers; sub-arrays

\section{INTRODUCTION}

The architecture for the third generation relay satellites to be launched into geostationary orbit (GEO) in the next decade or two is currently being investigated by NASA. The designated frequencies for the forward (GEO-to-LEO) and return links (LEO-to-GEO) are 22.55-23.55 GHz and 25.25$27.5 \mathrm{GHz}$, respectively. One of the primary roles of this satellite is to relay the data gathered from low Earth orbiting (LEO) science spacecrafts to ground stations.

Over the past few years significant advances in the area of Ka-band gallium nitride $(\mathrm{GaN})$ based solid-state power amplifiers (SSPAs) have been demonstrated [1]-[2]. These SSPAs are capable of delivering CW power as high as $36 \mathrm{~W}$ with a power added efficiency (PAE) of 30\% [1]. In addition, Ka-band direct radiating active phased array antennas (APAAs) capable of generating multiple simultaneous spot beams has been demonstrated [3]-[4]. Furthermore, multiGbps data rates using spectrally efficient waveforms, software defined modem, and Ka-band broadband high power amplifier have been demonstrated [5]. This paper presents the results of an ongoing study to investigate the feasibility of designing a direct radiating phased array antenna for limited field-of-view (LFOV). The paper is organized as follows: first, for a desired antenna gain and scan angle, the computed overall array size and the total number of array elements that are required are presented. Second, for a fixed number of array elements and desired beam width and scan angle, the computed desired edge of coverage (EOC) directivity and the optimum array element size are presented. Third, a schematic illustrating the arrangement of the optimum array elements in a square grid configuration leading to a hexagonal array is presented. Fourth, the design of the beam-forming network (BFN) using overlapped sub-array (OSA) techniques [6]-[9] for array excitation is presented. The advantages that OSA techniques offer for space aplications are first, the significant reduction in the number of control elements, such as variable gain amplifiers and phase-shifters, required to achieve the desired scan performance. Second, significant reduction in the array complexity, power consumption, overall size/mass, and cost. Third, enhanced overall antenna reliability.

\section{ARRAY DESIGN}

A direct radiating phased array antenna on a relay satellite in GEO above the Earths surface is illustrated in Fig. 1. At such a distance, the Earth subtends a small conical angle of $\theta$ $= \pm 8.7^{\circ}$. Consequently, the phased array onboard the relay satellite has to scan a LFOV.

\section{A. Array Size Versus Number of Array Elements}

The layout of the array and the co-ordinate system for antenna analysis are illustrated in Fig. 2. The scan angle $\theta$ about the nadir direction of a beam within the desired coverage is illustrated in Fig. 3. The diameter of the spot size on ground would be the width of the beam between its $3 \mathrm{~dB}$ points. The computed overall array size (A) as function of the total number of elements $(\mathrm{N})$ in the array for a desired antenna gain and scan angle is presented in Fig. 4. These computations were carried out using the equations presented in [10].

\section{B. Edge of Coverage Directivity Versus Array Element Size}

Square elements are considered with dimensions a $\mathrm{x}$ a and touching each other leaving no interelement spacing. The computed edge of coverage directivity as a function of the array element size using equations from [10] is presented in Fig. 5. The optium element size is also indicated in Fig. 5.

\section{Beam-Forming Network Using Overlapped Sub-Array Techniques}

Next, the elements are arranged in a square grid configuration leading to a hexagonal array, which approximates a circular aperture as illustrated in Fig. 6. In reality each element is a sub-array in itself containing several smaller antenna elements. For example, a sub-array with seven nearly square microstrip patch antennas for radiating a circular polarized (CP) wave [11] is illustrated in the inset in Fig. 6. The upper bound for LFOV scanning in one dimension for a sub-array spacing of a and scan angle $\theta$ is given by the following relationship:

$$
\left(\mathrm{a} / \lambda_{0}\right) \sin |\theta| \leq 0.5
$$

Where $\lambda_{0}$ is the free space wavelength. In the LFOV arrays, amplifiers and phase shifters are integrated only at the input port of each sub-array. The beam-forming network is designed 
as outlined in [6]-[9] and details will be presented at the symposium.

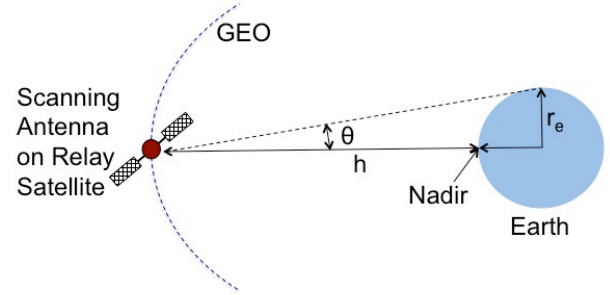

Fig. 1. A direct radiating phased array antenna located on a relay satellite in GEO above the Earths surface The altitude $\mathrm{h}=35,786 \mathrm{~km}$ above mean sea level and Earth's radius $\mathrm{r}_{\mathrm{e}}=6378 \mathrm{~km}$.

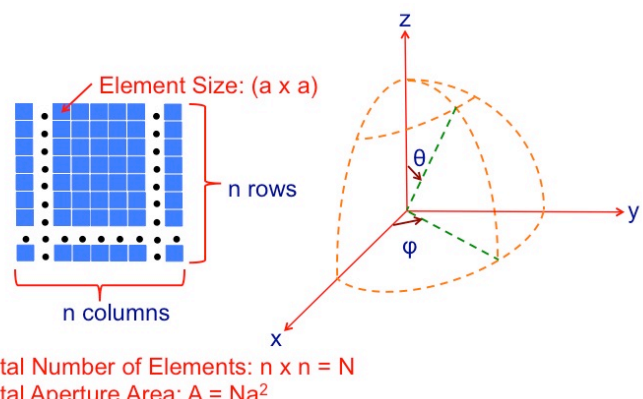

Fig. 2. Array antenna layout and coordinate system for analysis.

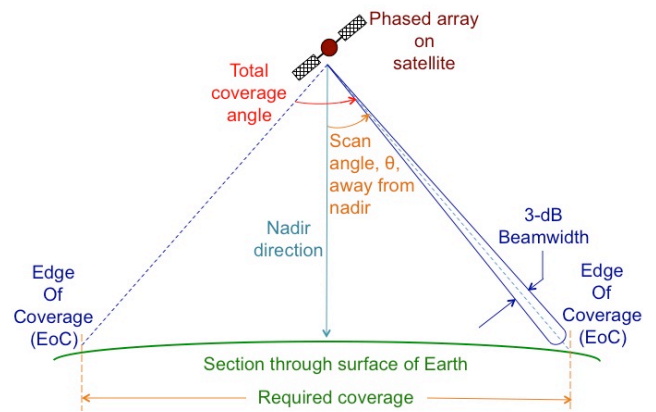

Fig. 3. Illustration of scan angle of an individual beam within coverage.

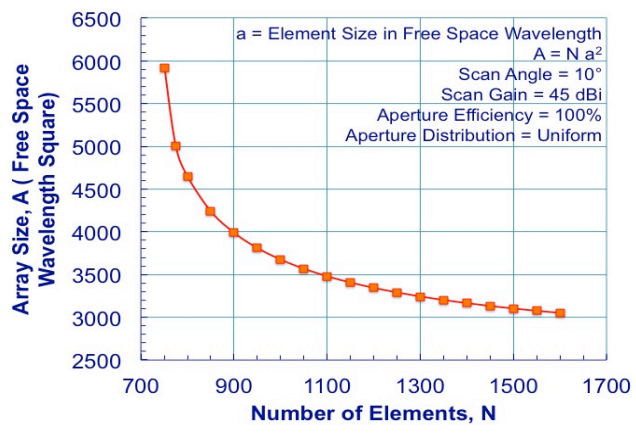

Fig. 4. Computed array size versus number of array elements.

\section{REFERENCES}

[1] S. Din, M. Wojtowicz, and M. Siddiqui, "High power and high efficiency Ka band power amplifier," 2015 IEEE MTT-S Inter. Microwave Symp. (IMS) Digest, pp. 1-4, Phoenix, AZ, May 17-22, 2015.

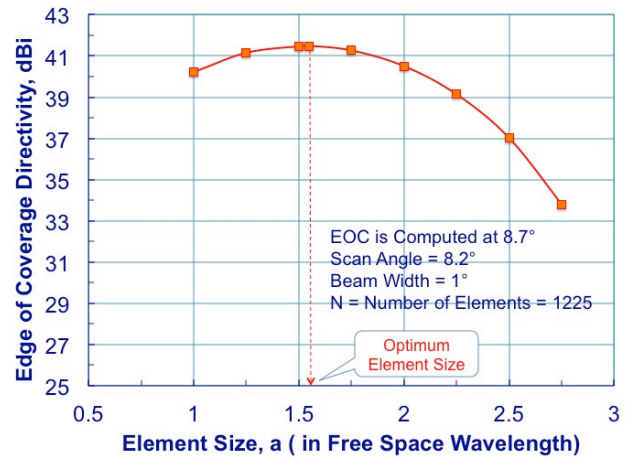

Fig. 5. Computed array element size versus the edge of coverage directivity.

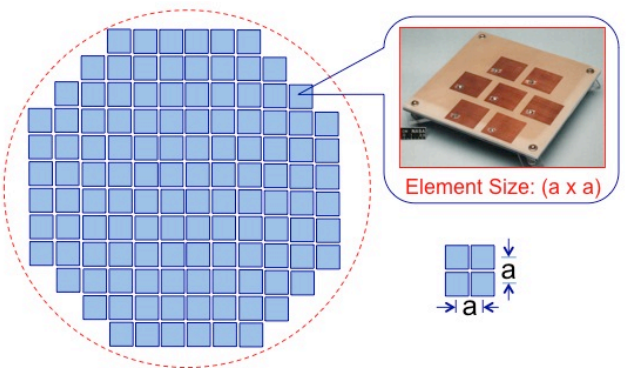

Fig. 6. Elements arranged in a square grid configuration, $\mathrm{a}=1.55 \lambda_{0}$.

[2] C.F. Campbell, Y. Liu, M.-Y. Kao, and S. Nayak, "High efficiency Kaband gallium nitride power amplifier MMICs," 2013 IEEE Inter. Conf. on Microwaves, Communications, Antennas and Electronics Systems (COMCAS) Digest, pp. 1-5, Tel Aviv, Israel, Oct 21-23, 2013.

[3] A. Akaishi, M. Iguchi, K. Hariu, M. Shimada, T. Kuroda, and M. Yajima, "Ka-band active phased array antenna for WINDS satellite," $21^{\text {st }}$ AIAA Inter Communications Satellite Systems Conf. and Exhibit, Paper Number AIAA 2003-2397, Yokohama, Japan, April 15-19, 2003.

[4] Y. Cailloce, G. Caille, I. Albert, and J.M. Lopez, "A Ka-band direct radiating array providing multiple beams for a satellite multimedia mission," Proc. of the 2000 IEEE Inter. Conf. on Phased Array Systems and Technology, pp. 403-406, Dana Point, CA, May 21-25, 2000.

[5] R.N. Simons, E.G. Wintucky, D.G. Landon, J.Y. Sun, J.S. Winn, and S.Laraway, W.K. McIntire, J.L. Metz, and F.J. Smith, "Demonstration of multi-Gbps data rates at Ka-band using software defined modem and broadband high power amplifier for space communications," 2011 IEEE MTT-S Inter. Microwave Symp. (IMS) Digest, pp. 1-4, Baltimore, MD, June 5-10, 2011.

[6] D. Petrolati, P. Angeletti, and G. Tosa, "A lossless beam-forming network for linear arrays based on overlapping sub-arrays," IEEE Trans. Antennas Propag., vol. 62, no. 4, pp. 1769-1778, April 2014.

[7] S. P. Skobelev, "Some features of the overlapped subarrays built up of beam-forming matrices for shaping flat-topped radiation patterns," IEEE Trans. Antennas Propag., vol. 63, no. 12, pp. 5529-5535, Dec 2015.

[8] R. J. Mailloux, Phased Array Antenna Handbook, 2nd ed. Norwood, MA, USA: Artech House, 2005.

[9] R. J. Mailloux, Electronically Scanned Arrays, San Rafael, CA, USA: Morgan \& Claypool, 2007.

[10] A.K. Bhattacharyya, "Optimum design considerationfor multiple spot beam array antennas," $22^{\text {nd }}$ AIAA Inter. Communications Satellite Systems Conf. \& Exhibit, Paper Number AIAA 2004-3158, Monterey, CA, May 9-12, 2004.

[11] R.N. Simons, R.Q. Lee, and G.R. Lindamood, "New coplanar waveguide/stripline feed network for seven patch hexagonal $\mathrm{CP}$ subarray," Electronics Lett., vol. 27, no. 6, pp. 533- 535, March $14^{\text {th }}$ 1991. 